\title{
Suspending the Passing of Sentence (Probation before Judgment)
}

\author{
Esmael Afrasiabi ${ }^{1} \&$ Mohammadali Kanani ${ }^{2}$ \\ ${ }^{1}$ LLD in Criminal Law and Criminology, Assistant professor of Islamic Azad University-Central Tehran Branch, \\ Faculty of Law, Iran \\ ${ }^{2} \mathrm{PhD}$ Student of Criminal Law and Criminology, Islamic Azad University- Central Tehran Branch, Faculty of \\ Law, Iran \\ Correspondence: Mohammadali Kanani, Tehran-Mohammadali Jinah St., Salehi Blvd., Southern Abbas Akbari \\ St., Shafiée St., No.5. Unit7., Iran. Tel: 21-6619-6861. E-mail: daneshjou139@gmail.com
}

Received: April 26, 2016 Accepted: June 3, 2016 Online Published: August 30, 2016

doi:10.5539/jpl.v9n7p206 URL: http://dx.doi.org/10.5539/jpl.v9n7p206

\begin{abstract}
Suspending the passing of sentence is one of the new establishments of the Islamic Criminal Code and in the legal system of our Country, Iran it lacks any legislative background. In this new establishment we are witnessing a specific approach towards individuals who have committed some minor crimes and the legislator for the sake of accommodating them with social norms and preventing the re commitment of the criminal acts in case of existence of necessary conditions has predicted the possibility of suspending their sentence. Suspending the passing of sentence or pronouncing judgment has been established based on the principle of individualizing the judicial procedure of punishments and is part of the institutions of pardon for the committers of crimes. In the present text besides discussing the issue in philosophical terms the fundamentals and the domain of suspending a sentence, its formative and substantial conditions is being studied and scrutinized.
\end{abstract}

Keywords: suspending the passing of sentence, simple suspension, observatory suspension, measurements and decrees, exemption from punishment decree

\section{Introduction}

Suspending the passing of sentence has been predicted for the first time in the history of legislation of Iran in the year 2013-2014 and is accounted for as one of the innovations this code. This establishment of the law has been patterned after the western countries and specifically the legal system of France (I.e. articles 60-132 onwards in the penal code of France) (Mosaddeq, 2013:135) The philosophy behind the this legal establishment which is constituted based on the labeling theory is that the court in some cases of minor crimes (i.e. The sixth degree and the eighth degree discretionary punishment) in case of presence of legal conditions become able to exempt the delinquent from punishment prevents him/her from being labeled as a guilty. This philosophy is the opposite of suspending the sentence in which the felon is sentenced to a punishment in the written judgment and then after setting up situations for an action the arranged and ordained punishment won't be put into effect.

In suspending to pronounce the judgment the court is allowed firstly to postpone the passing of the sentence and then exempt the delinquent from the preordained legal punishment in case making provisions for the legal requirements if the punishment won't be inflicted upon the wrongdoer. Suspending a sentence is based on the principle of individualizing the jurisdiction of punishments and by means of it the court gives the felon a chance until during his/her term of suspension accommodate himself/ herself by social norms and shuns from recommitment of a crime. This inclination of the legislator is compatible with the viewpoint of Islam and thinkers such as Rousseau who didn't consider the wrongdoers and felons as ill-natured individuals but individuals who may slip into wrongdoing; thus, the situation for correction and subduing the wrongdoers should always be prepared. Considering that this establishment has newly arisen in the law of Iran and it requires recognition and consideration of its pillars and conditions, aftermath, the competent authority to pronounce judgment, the formative and essential conditions of the verdict, and the factors of nullifying this nascent legal establishment until besides explaining the subject it becomes possible to witness the time for the attention of the courts and the legal society to this efficient establishment.

\section{Domain of Exercising the Suspension of the Sentence}

Suspension of a sentence according to the title of the article $40^{\text {th }}$ of the Islamic penal code is limited to the $6^{\text {th }}$ and 
$8^{\text {th }}$ classes' canonical punishment. Thus, the $1^{\text {st }}$ to $5^{\text {th }}$ classes of canonical punishments which fall under the regulations of suspension of the sentence don't fall under the canonical punishments which are stated in the unjuditialized Islamic canonical punishments and is different from it. According to the rider 2nd of the article 115 of the Islamic penal code the canonical punishments don't fall under the regulations of suspending the sentence. However, the legislator in the article forty seven (47) of the Islamic penal code has exempted some of the crimes from falling under the suspension rule. These offences which are enumerated in six articles are often offences that harshly disrupt the general order of society and from the point of view of the legislator the committer of it shouldn't go under or enjoy the institutions of pardon such as ampliation and suspension of the sentence or reprieve of penalty although scrutinizing these offences is indicative of the issue that they do not often go under the canonical punishment class six to eight; thus, it doesn't go under the suspension ab initio let alone requiring the allocation of suspension and according to the article $94^{\text {th }}$ of the Islamic penal code the whole canonical punishments which are committed by teenagers or juvenile canonical punishments can go under the regulations of suspending the sentence.

\section{Conditions for Investing the Decree of Suspending the Sentence}

\subsection{Substantial Conditions}

The First condition concerning the suspending of the sentence is 'the acknowledgement of the delinquency of the guilty". According to the title of the article $40^{\text {th }}$ of the Islamic penal code when the court can suspend the sentence until the conviction or guilt of the guilty gets decisive. Delinquency of the convict means that $\mathrm{s} / \mathrm{he}$ performs a deed which is considered as guilt according to the law and that deed can be attributable to him/her. Then if due to the lack of one of the three pillars of the intended guilt (i.e. Legal pillar, materialistic pillar, and intellectual pillar) has not occurred, or the deed is a guilt but there was no reason for the convict to do it or the deed is a guilt but the convict due to one of the accounts of obviation (i.e. obviatory reasons) such as minority or insanity become unpunishable and/or the performed deed is considered as one of the permitted reasons or justifications of guilt (i.e. obvious reasons of irresponsibility) in all of these cases due to the lack of delinquency of the convict and issuing the sentence of acquittal by the court there is no reason to suspend the sentence.

The second condition for enjoying the suspension of sentence is the merit of the guilty. According to the article forty of the Islamic penal code' 'The court can suspend the sentence after the acknowledgement of the guilt of the convict by considering the personal, familial, and social conditions and the background and situations or factors which have led to committing the crime." According to this, the court is bound to investigate the convict's history of life and background or criminal record. Despite the stipulation of the lawmaker this issue involves filing a document of personality for the convict.

The third condition based on the legal clause one of the article forty of the Islamic penal code suspension of the sentence involves the existence of several reasons for commutation of sentence. That is there should at least be one of the requirements for commutation of the punishment stipulated in the article thirty eight of the Islamic penal code which is applicable to the convict.

The fourth condition: another condition for the suspension of issuing the decree of punishment according to the legal clause two of the article forty of the Islamic penal code is "predicting the correction of the committer." The judge by considering the character, criminal record of the guilty, and also the conditions of the committed conviction should come to this conclusion that lack of issuing the sentence for such a convict will lead to his/her correction in future and prevents him/her from committing another crime. Thus, it is accepted that in cases which the convict has several criminal records and committing crimes has change into one of his/her habits or part and parcel of his/her life his/her correction is hardly predictable by suspending the issuing the decree of punishment.

The fifth condition: is "retaliation of the harms and losses or establishing the requirements of retaliation" Which are predicted in the legal clause three of the article forty of the Islamic penal code. In other words, indemnifying the relator or win the favor of him/her is among the requirements of investing the decree of suspending the sentence. This is against the suspension of issuing a sentence in which according to the article fifty one of the Islamic penal code indemnifying the relator for the loss is the requirement of enforcing the suspension of the punishment not the requirement of issuing or bestowing the decree of suspension.

The sixth condition to use the suspension of issuing the decree of punishment according to the legal clause four of the article forty of the Islamic penal code is the lack of any effective penal background or record. Effective conviction according to a rider of the above-mentioned article relevant to the article twenty five of the Islamic penal code by which the committer is realized to deserve the suspension of issuing the verdict when he/she doesn't have any decisive penal conviction for the intentional crimes as it has been described under the three mentioned legal clauses. The point which should be noted here is that it seems that the mere decisive conviction 
of the committer to one of the punishments which have been inserted in the article twenty five doesn't deprive $\mathrm{him} / \mathrm{her}$ of suspension of the issuing of the decree of punishment during his/her whole lifetime, but in case of expiration of the predicted dues or dates which are inserted in the article twenty five (i.e. Seven, three, and two years) and the rehabilitation of the convict his/her right to enjoy the suspension of issuing the decree of punishment is possible and authorized.

If the effective former conviction of the convict gets null and void due to some legal reasons such as pardon, abolishment of the law, and the pardon on behalf of the plaintiff in the pardonable crimes then it should be said that it is assumed that when the penal conviction gets null and void due to any reason it will no longer be considered as a criminal background for the guilty thus the verdicts of suspension of issuing the decree of punishment. (Ardebili, 2013: 220) At the end of this section it should be pointed out that suspension of issuing the verdict shouldn't be considered as a right for the guilty. In other words, as the whole requirements of investing the suspension is accessible and at hand it is in the hand of the court to make a decision by considering the conditions and the personality of the committer and according to it postpone the condemnation sentence or turn to introduce the condemnation sentence.

\subsection{Formative Conditions}

The first condition is that the suspension verdict to issue the final verdict should be issued after the acknowledgement of the guilt not before that. The verdict to suspend pronouncing the judgment is in the form of a warrant and issuing it is also necessary when the court after scrutinizing the committed action considers it as a crime and attributes it to the committer; here the court after scrutinizing the legal conditions turns to issue the suspension verdict. Thus, issuing this arrest warrant before acknowledging the delinquency of the convict lacks legal force and in case of issuing it will be followed by the Disciplinary conviction of the court. The question that comes to our heads here is that whether the acknowledgment of the delinquency of the convict will be postponed to issuing an independent verdict such as cases in the laws of states as England or the U.S.? In the law of the mentioned states opposite to Iran acknowledgement of the guilt of the culprit and inflicting penalty or animadversion for the culprit takes place in two independent phases and the account for it is that at the end of trial or court procedure the jury (in cases which the jury is not present in the court case) concerning that whether the culprit is guilty or innocent takes its decision. This decision-taking is called verdict. If the convict in this level become exculpated s/he will be exonerated and if the culprit will be called guilty a pre-arranged time will be determined for his/her animadversion or sentence hearing and the culprit can attend for sentence hearing or judicium but his/her attendance is not necessary. Both the culprit and the attorney general have the right to ask for (verdict on) judicial review. Also in suspending the issuing the verdict which is inserted in the Law of Iran the first issue is the acknowledgement of the guilt and after that at the end of the term of suspension the reason for the suspension to issue the verdict or inflicting the penalty is at hand. Deciding to consider that the criminal court in Iran is bound to introduce an independent sentence concerning the acknowledgement of the guilt of the culprit is hardly likely to add up to the present code and no coercion or obligation is being perceived in this case. By reminding that in the usual legal procedures in the courts of Iran acknowledgement of the guilt of the culprit and issuing the condemnation sentence occurs in one phase and by means of one verdict. (Not in two phases) Thus, a fortiori it will be acted upon the issue in suspending the issuing the verdict as well.

The second condition is that the court can't issue order to suspend the decree in absentia. (Rider one of the article forty one of the Islamic penal code) The court order to suspend the decree can be issued correctly when the court by considering the individual, familial, social, penal back ground, and the situations and the characteristics of the committed guilt in summary acknowledge the merit or deserve of the culprit to receive his/her sentence. This enterprise won't come true unless after the appearance of the culprit in the court. Conditions such as predicting the correction of the culprit, retaliation of the private plaintiff for the loss and a written guarantee submitted by the culprit for the non-commitment of the crime which has been predicted in the articles forty and forty one of the Islamic penal code which altogether make the appearance of the culprit in the trial session in order to issue the order to suspend the decree. Thus, although according to the article four hundred and six of the code of criminal procedure submitting the cross bill or introduction of the barrister the verdict will be performed in the culprit's presence not in absentia. But the issue that even in this case and by assuming the contumacy of the culprit the court will be able to issue the order to suspend the decree is hardly acceptable. The question which appears here is that if the court decided to introduce the sentence in absentia for the conviction of the culprit is it possible for the court to issue the suspension warrant? The answer to this question seems to be positive since suspension of issuing the decree is considered as one of the institutions of pardon for the culprits which shouldn't be considered as a mere contumacy of the culprit in the court and issue a verdict in absentia. It is mostly probable that contumacy of the culprit in some aspects be out of his/her will. 
Observation of the regulations or principles of a fair judgment and interpretation of the codes in favor of the culprit makes it necessary that in case of complaints from culprit for the verdict in absentia and holding a court session issuing the order to suspend the decree is free from legal impediments.

\section{Competent Authority for Suspension of Issuing the Decree}

According to article forty of the Islamic penal code the competent authority for the suspension of issuing a decree is the court which after the acknowledgment of the guilt by considering the situation, criminal background, and the situations and qualifications of the case suspends the issuing of the verdict. Thus, the office of public prosecutor as an institute for prosecuting the wrongdoers concerning the issuing of the suspension warrant is ineffective. Also, this warrant is considered as one of the exceptionable warrants of the criminal courts according to the rider two of the article four hundred and twenty seven of the code of criminal procedure which is enacted in the year 2013-2014.

\section{Aftereffects of the Suspension of Issuing the Decree}

The legislator has determined the ordained term for the suspension of issuing the decree by six months up to two years. The court can merely issue a verdict in this domain for the suspension of issuing the verdict. This term (i.e. Six months to two years) is exactly compatible with the term of the determined or ordained imprisonment for the sixth degree canonical punishment which is inserted in the article nineteen of the Islamic penal code. Although the court has free hand in exercising this minimal and maximal punishment limit but if in a case the court determine the sentence of the culprit as an imprisonment the maximum amount of the term of suspension in accordance with the maximum amount of the term of legal imprisonment of the culprit it has abided by a correct legal logic. For instance, in a crime such as hiding or burial of the body of the murdered individual according to the article six hundred and thirty six of the canonical punishments code in which the maximal amount of the punishment for the culprit is one year imprisonment in case the court was about to suspend the issuing of the verdict determining the term or duration of the suspension of issuing the verdict for a term of one year or less than that is better and is finally appropriate for the situation of the culprit and is in accordance with the criminal justice.

By issuing the warrant for the suspension of issuing the verdict the court gets free from introducing the conviction decree for the committer and in case of arresting the culprit the court should pass a sentence to release the offender or culprit. Rider two of the article forty of the Islamic penal code ordains that: 'In case the culprit is imprisoned, the court after issuing the warrant for the suspension of issuing the verdict immediately passes a sentence to release him/her. The court can take the proper or relevant permit from the court to do the first legal actions to prevent the culprit from hiding or escaping and the ability to access the culprit at any time by the judge to appear in the court. In any case taking this permit shouldn't lead to arresting the culprit. " Arresting the culprit before judgment or trial is due to issuing one of the criminal court permits to prevent the hiding or escaping of the culprit either it is due to issuing the mentioned permit which is temporary or whether it may happen due to issuing other permits to prevent hiding or escaping the culprit before appearing in the court for the cases of security, bail, incapability of the culprit to introduce a mandatory or deliver a security. In any case by issuing the suspension warrant of issuing the verdict the imprisonment of the culprit should be cancelled and $\mathrm{s} /$ he should be set free right away.

Concerning the suspension of issuing the verdict in punishments which are for the sake of security or corrective purposes and are intended to prevent the occurrence of the guilt throughout deactivating the dangerous situation such as confiscating the instruments of crime or destroying them (i.e. Article seven hundred and nine of the canonical punishment code) or confiscating and restitution of stolen goods which are attained out of crime(article seven hundred and twelve and seven hundred and thirteen from canonical punishment code). It seems that suspending the issuing the verdict is against the philosophy behind such punishments and they shouldn't fall under the regulations on suspending the issuing of the verdict.

It was mentioned that the suspension term is six months to two tears. In this tentative term the culprit for whom the issuing of sentence has been postponed in case the crime doesn't involve the punishments of penance, retaliation, deliberate murder which enjoys blood money or canonical punishment up to grade seven and also in execution of the court orders in the time of observatory suspending doesn't lead to issuing the verdict of punishment for the convict (article forty four of the Islamic penal code), then the culprit can achieve the requirements of bestowing the impunity. Article forty five of the Islamic penal code ordains that: "after the passage of the term of suspension by considering the degree of abidance of the culprit by the execution of the court decrees, the report of the social worker, and also considering the situation of the culprit the court will act to determine the punishment or issuing the decree of suspension from punishment." From the appearance of the 
mentioned article it can be deduced that after the expiration of the tentative term the court has an absolute free hand in determining the punishment or issuing the decree of suspension from punishment but by scrutinizing the article forty five of the Islamic penal code and its final section which says: "the court takes action according to the case to determine the punishment or issues the decree of suspension from punishment." It is deduced that after the expiration of the term of suspension (i.e. the tentative term) two assumptions are imaginable: Firstly, If the committer during the term of suspending observes the decrees and the legal measures which are inserted in the articles forty two and forty three of the Islamic penal code; Secondly, If the committer during the term of suspension observes the decrees and the legal measures. In the first assumption by complete obedience of the decrees and measures by the culprit issuing the decree of suspension of punishment for the committer is logically inevitable and the court acts to issue the decree of suspension of punishment for the culprit. The second assumption is that if the culprit observes some of the decrees and legal measures but in the eyes of the court inobservance of these rules by considering the situation of the culprit and the situations and requirements of the court case may don't bear a considerable significance. Also in this case the article forty five of the Islamic criminal code is to some extent flexible that the court by resorting to it can exempt the culprit from punishment. But if the culprit doesn't observe the whole or part of the decrees and legal measures and in view of the court nonobservance of these measures bears a considerable significance in a way that the actualization of the purposes of suspension of issuing the verdict such as predicting the correction and the compatibility of the culprit with the social norms are being put into doubt, in this case the court will be able to exercise a correct legal and judicial logic by determining the punishment for the culprit.

In the recent assumption that is the place which the warrant of suspension at the end of the term of suspension in lieu of the exemption of the culprit from punishment leads to the issuing of the decree of punishment and the nonobservance of the decrees and the measures by the culprit leads to the failure of this establishment, elongation of the court hearing occurs in the comparatively minor crimes and we are witnessing the annexation of a network to the steps of criminal court hearing which is called "suspension". Although this issue as one of the rare pitfalls of this legal establishment, it is worthy of consideration but this fault in contrast with its privileges and accents doesn't bear such a power that causes the inefficiency of this establishment.

Within the domain of the just causes such as legitimate defense and the order of the law in fact no crime takes place. Concerning the just causes to side step the criminal responsibility such as insanity and infancy no crime takes place but it isn't attributable to the culprit and the criminal responsibility doesn't actualize. In all of these cases the court verdict will be based on the acquittance or acquittal of the culprit but in suspending the issuing of the verdict a crime has occurred and it is capable of attributing to the culprit but the legislator by considering the conditions and after the actualization of them suspends the culprit of punishment and doesn't clear or acquit him/her. Exemption or acquittance of the committer of a crime involves just the punishment and the civil responsibility of the culprit and paying the costs of trial will be up to him/her. Also, the crime is registered in the criminal record of the culprit and it will be influential in his/her future records. However, issuing the suspension warrant and a warrant for exemption from punishment is merely ineffectual for the individual for whom this warrant and exemption from punishment have been issued and it is ineffectual for his/her accomplices and the particepe criminis.

\section{Vacation of the Suspension Warrant to Issue the Verdict}

In case of existing required conditions the court issues the suspension warrant to issue the verdict. Suspension can be either simple or observatory. Concerning this issue the article forty one of the Islamic penal code ordains that: "Suspension of verdict is either simple or observatory. 1-In the simple suspension the culprit submits a written guarantee that during the determined term by the court doesn't commit any crime and it will be predictable from his/her conduct that s/he will never commit any crime in future. 2-In observatory suspension in addition to the conditions of the simple suspension the culprit commits to observe the decrees and the measures which are ordained by the court during the term of suspension or performs them."

Term of suspension to issue the verdict which its duration is from six months to two years is not the period in which the culprit bears a right for an absolute freedom. In this term in addition to submitting a written guarantee by the for the non-commitment of the crime in case his/her suspension is an observatory one in addition to observing the ordained legal measures which are inserted in the article forty two of the Islamic penal code and the orders of the court which are inserted in the article forty three of the Islamic penal code in the suspension term. The article number forty two of the Islamic penal code says that:

Observatory suspension is accompanied by the following measures:

1) On time appearance in the court in the arranged time and place by the legal authority or the superintendent 
social worker.

2) Submitting the facilitating information and documents for supervising the execution of the commitments of the culprit for the social worker.

3) Announcing any kind of change in job, residence, or any kind of replacement in a period less than fifteen days and submitting a report on it to the social worker.

4) Taking permission from legal authority in order to travel abroad. Rider: The above-mentioned measures from court can be accompanied by some legal assisting measures such as introducing the culprit to the supporting institutions.

The predicted measures in this article by considering its rider takes a symbolic form and the court can oblige the culprit to some more obligations than what is inserted in this article.

Article number forty three of the Islamic penal code states: "In the observatory suspension the court which issues the warrant can oblige the culprit to execute one or more of the following orders during the term of suspension by considering the committed crime and the characteristics of the committer and his/her living condition in a way that it doesn't lead to a radical disruption in his/her life and his/her family:

1) Vocational education or having a specific job.

2) Residence or non-residence in a definite place.

3) Curing a disease or getting one off drugs.

4) Paying the alimony to the real beneficiaries of it.

5) Avoidance of filling the total or partial possession of some vehicle.

6) Avoidance of any professional activity relevant to the committed crime or making an effective use of it.

7) Avoidance of any relationship or association with the accomplices or accessories or any other person such as the victim by the recognition of the court.

8) Attending an educational program or programs peculiar to learning and educating the essential skills of life or attending the educational, moral, religious, academic, or athletic programs.

These decrees contrary to the legal measures which are inserted in the article forty two of the Islamic penal code are not exclusive. The force for the non-observance of the court decrees based on the final section of the article forty three of the Islamic penal code consists in: "The judge can issue the sentence verdict just one time up to the half of the determined period in the arrestment warrant."

The legislator in the article forty four of the Islamic penal code predicts the non-execution of the court decrees during the term of suspension of the necessary force for the verdict but concerning the non-execution of the arranged measures in the article of the Islamic penal code no specific force has been predicted by the law. Approval of this idea that the final section of the article forty four of the Islamic penal code concerning "'the non-execution of the court decrees" whether the ordained decrees by the court and the legal measures and lack of statement of the measures out of the fault of the legislator seem to be unjustified due to two reasons. Firstly, the legislator by introducing the legal measures and decrees in the two independent articles that are articles forty two and forty three of the Islamic penal code clearly draws a distinction between them. In the clause (b) of the article forty one of the Islamic penal code some measures and decrees are declared independently. Secondly, the legal principles such as interpreting the criminal legal voids the interpretation is in favor of the culprit and observing the rights of the culprit is against this view and questions any permission to approve it. Thus, the question which arises here is that non-execution of the determined legal measures in the article forty two of the Islamic penal code during the term of suspension brings about what kind of force for the culprit? The answer to this question is that non-execution of the legal measures during the term of suspension or the tentative term of "six months to two years" lacks any force but at the end of suspension term the court can enforce or exercise the arranged legal punishment in lieu of issuing the decree of exemption from punishment. In the article forty five of the Islamic penal code besides the court decrees the "report by the social worker and also considering the situation of the culprit" is stated which by contrasting and considering it beside the article forty two of the Islamic penal code we can realize the relation and the indication of this section of the article forty five to the predicted legal measures in the article forty two and its clauses.

Committing a crime in the suspension term is one of the reasons for cancelling the writ of suspending the issuing the decree. According to the article forty four of the Islamic penal code: 'During the term of suspension in case of committing a crime which deserves penance, Islamic retaliation, intentional homicide, which deserve 
receiving blood money or canon up to seventh degree the court issues a decree of cancellation of the writ of suspension of any issues the decree of conviction." Also, in case of cancelling the writ of suspension and issuing the conviction sentence issuing the suspension writ to execute the punishment is forbidden. (Rider two of the article forty four of the Islamic penal code)

It should be noted that although the legislator obliges the court to issue measures and decrees which are ordained in the articles forty two and forty three of the Islamic penal code to make them understood but doing this thing by considering the observation of the rights of the culprit is inevitable.

Is the mere commitment of the predicted crimes in the article forty four of the Islamic penal code can lead to cancelling the suspension warrant or these crimes should lead to a decisive conviction and after that the court which issues the writ of suspension acts to cancel it? It should be answered that although in the article forty four of the Islamic penal code there is no hint to a decisive conviction but observation of the rights of the culprit and the legal and legislative logic requires that after the commitment of the crime by the culprit and the decisiveness of the verdict the court which issues the decree to suspend the issuing the verdict cancels it. It is mostly probable that the culprit in the time of committing the crime lacks any ill will or his/her crime is unattributable or his/her deed goes under one of the justified factors of crime (i.e. real cause of irresponsibility) so no punishment is conceivable for him/her. Thus, according to the content of the article fifty four of the Islamic penal code despite the lack of stipulation of the legislator the final conviction (not the mere commitment of the crime) should be considered as the criterion for the cancelling the writ of suspension. (Theory No.6/8/1392-1462/92/7)

Questions that may arise are that if during the arranged term for the suspension of the issuing the verdict (i.e six months to two years) the culprit submits new evidence or proofs about his/her innocence to the court that issues the verdict is the court allowed to consider and investigate these new proofs or not? The balancing point of this answer lies in this point that we consider the warrant of suspending the verdict as a final warrant for the court or not. By approving that the final warrants of the court bear two principal features: Firstly, issuing these warrants causes the procedure of hearing and investigating the intended crime in the court of the first instance (contrary to the warrants such as inefficiency warrant) and the other point is that it takes the court under the umbrella of the rule of exemption of the legal arbitrator since after its issuing by the court at the end of the term of suspension the court leaves the case open to investigation. Thus, this warrant doesn't bear the main feature of the final warrant which is the exact rule of exemption of the arbitrator and is not considered as a final warrant. Thus, in case the court submits new evidence on the innocence of the culprit the court sees no problem or legal impediment in investigating and perhaps issuing the absolvitor.

\section{Conclusion}

The legislator in the year 2013-14 in Iran by viewing the laws in other states and making use of their experiences such as the criminal code of France (i.e. Articles 60-132 onwards) turns to creating the legal establishment of suspending the issuing the verdict. Considering that the main pillars of this establishment is based on re-socializing the culprit giving a chance to him/her to accommodate with the social norms and preventing the recommitment of the crime its efficiency depends on the observatory suspension for the perfect and correct performance of these measures and decrees and which are stipulated in the law by the culprit and exercising a close observation on the appropriateness of performing the legal measures and decrees. In other words, the court should finally makes sure by investigating the deeds of the culprit in the suspension term and by making sure of it introduces to write the decree of suspension from punishment. The expressed censure to the legislator in the year 2013-14 is that in spite of the prediction of the varied and new institutions of pardon in the Islamic penal code but most of them are applicable to the crimes with minor punishments such as the legal establishment of suspending the issuing of the verdict which its accounts have been inserted in this essay. Thus, it is necessary for the legislator to review this tentative law and take measures until itsestablishments of clemency such as suspending the issuing the verdict merely involve the relatively unalleviated crimes and the domain of exercising of them expands for the crimes until the judges and the persecutors of the courts make use of them with a more free hand.

\section{References}

Adelnia Najafabadi, M. (2011). Suspension of issuing the verdict in the penal code of Iran and scrutinizing the function of the Iranian legislator. MA thesis proposal. University of Judicial sciences and the administrative services.

Afrasiabi, E. (1997). Common penal code (1st ed.). Tehran. Mizan Publication.

Amirsamavati, P. (2004). Penal Code of the U.S. (1st ed.). Negah-e-bayeneh Publication. 
Ansari, W. (2001). Criminal investigations Code (1st ed.). Tehran. SAMT.

Ardebili, M. (2013). Interviewing the Keyhan Paper. No.2531.

Ardebili, M. (2014). Common penal code (1st ed., Vol. 3). Tehran. Mizan Publication.

Fletcher, G. P. (2005). Basic concepts of Criminal Law (15th ed.). Mashad. Translated by Mahi Seyyedzadeh sani. Razavi University of Islamic Sciences Publication.

Mosaddegh, M. (2013). Explanations on the Islamic penal code (3rd ed.). Tehran. Jangal-e-javdaneh Publication.

Qiasi, J., \& Heidari, M. (2012). An essay on investigating the suspension of issuing the verdict in the act of Islamic penal code. Journal of Criminal code and Criminology, (1).

Scheb, J. M., \& John, M. (1999). Scheb II. Criminal Law and Procedure.

Zeraát, A. (2013). Common penal Code (1st ed.). No.3. Jangal-e-javdaneh Publication.

\section{Copyrights}

Copyright for this article is retained by the author(s), with first publication rights granted to the journal.

This is an open-access article distributed under the terms and conditions of the Creative Commons Attribution license (http://creativecommons.org/licenses/by/4.0/). 